\title{
Fish oil and inflammatory status alter the n-3 to n-6 balance of the endocannabinoid and oxylipin metabolomes in mouse plasma and tissues
}

\author{
Michiel G. J. Balvers $\cdot$ Kitty C. M. Verhoeckx • \\ Sabina Bijlsma • Carina M. Rubingh · Jocelijn Meijerink • \\ Heleen M. Wortelboer $\cdot$ Renger F. Witkamp
}

Received: 2 December 2011/Accepted: 23 March 2012/Published online: 11 April 2012

(C) The Author(s) 2012. This article is published with open access at Springerlink.com

\begin{abstract}
It is well established that dietary intake of n-3 fatty acids is associated with anti-inflammatory effects, and this has been linked to modulation of the oxylipin and endocannabinoid metabolomes. However, the amount of data on specific tissue effects is limited, and it is not known how inflammation affects this relation. In the present study we systematically explored the combined effects of n-3 fatty acid diets and inflammation on the in vivo endocannabinoid and oxylipin metabolomes using a multicompartment, detailed targeted lipidomics approach. Male C57BL/6 mice received diets containing 0 , 1 , or $3 \% \mathrm{w} / \mathrm{w}$ fish oil (FO) for 6 weeks, after which $2 \mathrm{mg} / \mathrm{kg}$ LPS or saline was administered i.p. Levels of endocannabinoids $/ N$ acylethanolamines (NAEs) and oxylipins, covering n-3 and $\mathrm{n}-6$ fatty acid derived compounds, were determined in plasma, liver, ileum and adipose tissue using LC-MS/MS. FO generally increased ' $n-3$ ' NAEs and oxylipins at the expense of compounds derived from other fatty acids, affecting all branches of the oxylipin metabolome. LPS generally increased levels of endocannabinoids/NAEs and oxylipins, with opposing effects across plasma and tissues. Multivariate data analysis revealed that separation between diet groups in the saline treated groups was primarily
\end{abstract}

Electronic supplementary material The online version of this article (doi:10.1007/s11306-012-0421-9) contains supplementary material, which is available to authorized users.

M. G. J. Balvers $(\bowtie) \cdot$ J. Meijerink · R. F. Witkamp Division of Human Nutrition, Wageningen University, PO Box 8129, 6700 EV Wageningen, The Netherlands e-mail: michiel.balvers@wur.nl

M. G. J. Balvers · K. C. M. Verhoeckx ( $₫)$. S. Bijlsma .

C. M. Rubingh · H. M. Wortelboer

TNO, PO Box 370, 3700 AJ Zeist, The Netherlands

e-mail: kitty.verhoeckx@tno.nl explained by decreases in other than $\mathrm{n}-3$ derived compounds. In the LPS treated groups, the separation was primarily explained by increases in $\mathrm{n}-3$ derived compounds. In conclusion, FO caused marked changes in the n-3 to $n-6$ balance of the endocannabinoid and oxylipin metabolomes, with specific effects depending on inflammatory status.

Keywords Endocannabinoids - Oxylipins - Fish oil · Inflammation - Lipidomics - Multivariate data analysis
Abbreviations
2-AG
$\mathrm{ACN}$
2-Arachidonoyl glycerol
AEA
ARA
Acetonitrile
COX
Arachidonoyl ethanolamide
CYP450
Arachidonic acid
DGLEA
Cyclooxygenase
DHA
Cytochrome P450
DHA Docosahexaenoic acid
DHEA Docosahexaenoyl ethanolamide
DiHDoHE Dihydroxydocosahexaenoic acid
DiHETrE Dihydroxyeicosatrienoic acid
(also abbreviated as DHET)
DiHOME Dihydroxyoctadecenoic acid
DiHoPE Dihydroxydocosapentaenoic acid
(also abbreviated as DiHDPA)
EET Epoxyeicosatrienoic acid
EPA Eicosapentaenoic acids
EPEA Eicosapentaenoyl ethanolamide
FO Fish oil
HDoHE Hydroxydocosahexaenoic acid
HEPE Hydroxyeicosapentaenoic acid
HETE Hydroxyeicosatetraenoic acid 


\begin{tabular}{|c|c|}
\hline HHTrE & Hydroxyheptadecatrienoic acid \\
\hline HODE & Hydroxyoctadienoic acid \\
\hline HOME & Hydroxyoctadecenoic acid \\
\hline LA & Linoleic acid \\
\hline LC-MS/MS & $\begin{array}{l}\text { Liquid chromatrography-tandem } \\
\text { mass spectrometry }\end{array}$ \\
\hline LPS & Lipopolysaccharide \\
\hline LOX & Lipooxygenase \\
\hline LT & Leukotriene \\
\hline NAE & N-Acyl ethanolamine \\
\hline OEA & Oleoyl ethanolamide \\
\hline PEA & Palmitoyl ethanolamide \\
\hline PG & Prostaglandin \\
\hline PUFA & Polyunsaturated fatty acid \\
\hline SEA & Stearoyl ethanolamide \\
\hline TBX & Thromboxane \\
\hline
\end{tabular}

\section{Introduction}

Dietary intake of long-chain $\mathrm{n}-3$ polyunsaturated fatty acids (PUFAs), like docosahexaenoic acid (DHA; 22:6 n-3) and eicosapentaenoic acid (EPA; 20:5 n-3), is known to have beneficial health effects in both humans and animals, which are partly explained by a reduction of inflammatory processes (Calder 2006, 2009a; Carpentier et al. 2006; Schmitz and Ecker 2008). The mechanisms behind this are not completely understood, but involve binding of n-3 PUFAs to GPR120 (Oh et al. 2010), their conversion to resolvins (Serhan et al. 2004), and the alteration of the eicosanoid balance (Calder 2009a). Increased dietary intake of n-3 PUFAs leads to enhanced incorporation of DHA and EPA in cell membranes, at the expense of incorporation of the n-6 PUFA arachidonic acid (ARA; 20:4 n-6). This results in decreased synthesis of ARA-derived eicosanoids, for example $\mathrm{PGE}_{2}$, after e.g. an inflammatory stimulus (Calder 2009b). At the same time, increased levels of $n-3$ fatty acid derived eicosanoids are observed. These n-3 fatty acid derived metabolites are often referred to as '3-series' or '5-series' oxylipins, comprising structures like prostaglandin $\mathrm{D}_{3}$ $\left(\mathrm{PGD}_{3}\right), \mathrm{PGE}_{3}$, thromboxane $\mathrm{B}_{3}\left(\mathrm{TBXB}_{3}\right)$, and 5-hydroxyeicosapentaenoic acid (5-HEPE), or leukotriene $\mathrm{B}_{5}$ $\left(\mathrm{LTB}_{5}\right)$, respectively (see Fig. 1 for an overview of oxylipins and their origin). These compounds are in general also pro-inflammatory, but considered less potent than the ARA-derived metabolites under certain circumstances, thereby contributing to a reduction of the general inflammatory status and specific inflammatory processes associated with fish oil (FO) consumption (Calder 2006, 2009a; Schmitz and Ecker 2008).
Over the last decades, several endocannabinoids and related $N$-acyl ethanolamines (NAEs) have emerged as important regulators of metabolism and inflammation (De Petrocellis et al. 2000; Di Marzo 2008; Matias et al. 2006; O'Sullivan 2007). Like the oxylipins, these compounds are also derived from fatty acids following incorporation in cell membranes (Bisogno 2008; Ueda et al. 2010). Arachidonoyl ethanolamide (anandamide, AEA) and 2-arachidonoyl glycerol (2-AG) are two endocannabinoids which are derived from ARA, but combinations derived with other fatty acids also exist, such as palmitoyl ethanolamide (PEA) and the n-3 fatty acid derived NAEs docosahexaenoyl ethanolamide (DHEA), eicosapentaenoyl ethanolamide (EPEA). Both AEA and PEA are known for their anti-inflammatory properties (Cencioni et al. 2010; Re et al. 2007).

Several in vitro and animal studies have demonstrated a link between availability of specific fatty acids in the diet and the presence of endocannabinoids and related NAEs. Berger and coworkers reported enhanced levels of anandamide and 2-AG in piglet brain after feeding milk supplemented with ARA, with a diet rich in DHA showing even higher levels of its NAE metabolite, DHEA (Berger et al. 2001). Wood and coworkers showed that a two-week diet rich in DHA elevated plasma and brain levels of DHEA in mice, while decreasing plasma 2-AG (Wood et al. 2010). Artmann and coworkers demonstrated that feeding rats a FO diet, by nature rich in n-3 PUFAs, decreased jejunal levels of AEA and PEA, but increased the levels of n-3 NAEs DHEA and EPEA (Artmann et al. 2008). Fish oil also decreased adipose tissue levels of AEA and 2-AG in a rat model of obesity (Batetta et al. 2009). It thus seems that the profile of NAEs represents the relative abundance of fatty acids in the diet. Recently, is was shown that DHEA and EPEA display anti-inflammatory properties in macrophages and adipocytes (Balvers et al. 2010; Meijerink et al. 2011), indicating that these compounds might be involved in the anti-inflammatory effects which are related to dietary n-3 PUFA intake.

In addition to diet, inflammation is known to affect the synthesis and/or release of both oxylipins and NAEs (Maccarrone et al. 2001), but it is not known how inflammation itself affects e.g. DHEA and EPEA tissue levels in vivo. Moreover, it is not known if changes induced by dietary fatty acids also persist under inflammatory conditions, or if the effect of diet is different under inflammatory conditions.

In the present study, we systematically explored in detail the (combined) effect of dietary FO and inflammation on levels of endocannabinoids/NAEs and oxylipins in plasma, liver, ileum and adipose tissue of wild type C57BL/6 mice using a targeted lipidomic approach. In total, levels on 61 compounds were analyzed, including levels of $\mathrm{PGE}_{3}$, 

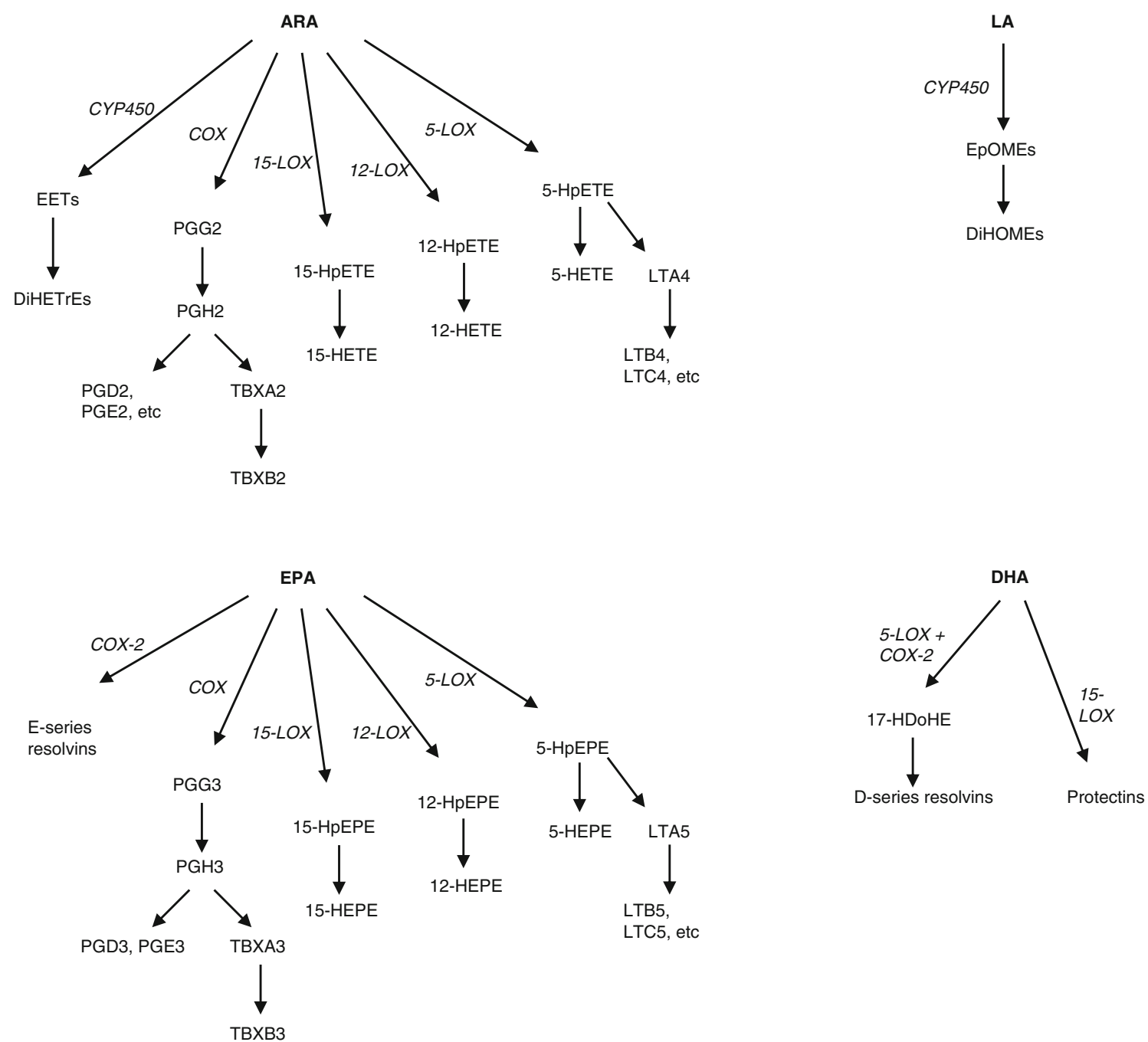

Fig. 1 Overview of several enzymatic pathways involved in oxylipin synthesis, which are under investigation in the present paper. ARA, LA, EPA and DHA can serve as substrates, yielding distinct oxylipins and intermediates

$\mathrm{PGD}_{3}, \mathrm{TBX}-\mathrm{B}_{3}, 5-\mathrm{HEPE}$, resolvin $\mathrm{D}_{1}$, DHEA and EPEA. Both univariate and multivariate data analysis tools were used to assess differences in metabolite patterns between the intervention groups. Our data show in detail that dietary intake of FO shifted the n-3 to $n-6$ balance in the endocannabinoid and oxylipin metabolomes in all tissues examined. In addition, the direction of this shift appeared to be affected by inflammation, and was different between the examined tissues.

\section{Materials and methods}

\subsection{Chemicals and reagents}

Lipopolysaccharide (0111: B4; LPS), indomethacin, paraoxon and butylated hydroxytoluene (BHT) were from Sigma (Steinheim, Germany). Phenylmethylsulfonyl fluoride
(PMSF) was from Fluka (Steinheim, Germany). 12-[(tricyclo[3.3.1.13,7]dec-1-ylamino)carbonyl]amino]-dodecanoic acid (AUDA) and URB602 was purchased from Cayman (Ann Arbor, MI, USA). Milli-Q water (Milli-Q Advantage unit, Millipore, Amsterdam, The Netherlands) was used in all analyses. ULC-grade acetonitrile (ACN), formic acid (FA) and trifluoro acetic acid (TFA) were obtained from Biosolve (Valkenswaard, The Netherlands). LC-MS grade methanol was from Riedel-de-Häen (Steinheim, Germany). Isopropanol and ethanol were from JT Baker (Deventer, The Netherlands). All analytical and internal standards, except EPEA, were purchased from Cayman. EPEA was synthesized as described earlier (Plastina et al. 2009a). For oxylipins, stock solutions were prepared in ethanol, aliquoted and stored at $-80{ }^{\circ} \mathrm{C}$ until analysis. For endocannabinoids/ NAEs, stocks were prepared in ACN, aliquoted and stored at $-80{ }^{\circ} \mathrm{C}$ until analysis. C8 SPE columns (Bond Elut; $200 \mathrm{mg}$, $3 \mathrm{~mL}$ ) were from Varian Inc. (Lake Forest, CA, USA). HLB 
SPE columns (Oasis, $60 \mathrm{mg}, 3 \mathrm{~mL}$ ) were from Waters (Etten-Leur, The Netherlands). ELISA kits were from R\&D Systems (Minneapolis, MN, USA).

\subsection{Animal experiment}

Wild type male C57BL/6 mice were obtained from Harlan (Horst, The Netherlands) and housed two or three per cage in a temperature controlled environment with a $12 \mathrm{~h}$ lightdark cycle (light at 6.00-18.00). The mice, 4 weeks old at arrival, had free access to a standard run-in diet (AIN93-M, with a $4 \% \mathrm{w} / \mathrm{w}$ fat content whereof $1 \%$ soy bean oil and $3 \%$ high-oleic acid sunflower oil (HOSF)) for 2 weeks. At the age of 6 weeks the mice were divided into three groups of 16 mice; group 1 was kept on the standard diet (control diet), group 2 received a diet containing AIN93-M with $1 \%$ fish oil (1\% FO diet) $\left(\mathrm{Marinol}^{\circledR}\right), 2 \% \mathrm{HOSF}$, and $1 \%$ soy bean oil. The third group had access to a diet containing AIN93-M with $1 \%$ soy bean oil and $3 \%$ fish oil (3\% FO diet). The diets and water were available ad libitum. Diets were prepared by Research Diet Services (Wijk bij Duurstede, The Netherlands) and the Marinol ${ }^{\circledR}$ was a kind gift from Lipid Nutrition (Wormerveer, The Netherlands). Diets were stored in air-tight bags at $-20{ }^{\circ} \mathrm{C}$ until just before feeding, and fresh food was provided two times per week to minimize oxidation of the fatty acids in the diet. GC-MS based analysis of the diets confirmed that the correct amounts of DHA and EPA were present, and re-analysis after 4 weeks revealed that its amounts were stable under the described conditions (data not shown). Food consumption and animal weight were measured two times per week, revealing no differences between the diet groups.

The diets were continued for 6 weeks, after which the animals received either i.p. saline (eight mice per diet group) or $2 \mathrm{mg} / \mathrm{kg}$ LPS (eight mice per diet group). After $24 \mathrm{~h}$, the animals were anesthetized, blood was collected from the orbital sinus and captured in $1.3 \mathrm{~mL}$ EDTA coated tubes (Sarstedt; Etten-Leur, The Netherlands) and put on ice until centrifugation $\left(10^{\prime}, 10,000 \mathrm{rpm}\right.$ at $\left.4{ }^{\circ} \mathrm{C}\right)$. After centrifugation, plasma was aliquoted. For oxylipin analysis, $200 \mu \mathrm{L}$ plasma was stored in $1 \mathrm{~mL}$ methanol containing paraoxon, BHT, AUDA, indomethacin, and PMSF to prevent oxylipin oxidation and breakdown. For endocannabinoid/NAE analysis, $100 \mu \mathrm{L}$ plasma was stored in the presence of PMSF and URB602. Subsequently, the animals were sacrificed by cervical dislocation after which liver, ileum and adipose tissue were collected and immediately snap-frozen in liquid nitrogen. All plasma and tissue samples were stored at $-80{ }^{\circ} \mathrm{C}$ until further analysis. Analysis of plasma IL- 6 and MCP-1 levels confirmed that LPS had triggered an inflammatory response by showing strongly increased IL-6 and MCP-1 levels in LPS-treated mice (data not shown).
The study was conducted according to the Netherlands Law on Animal Experiments, and approved by the local Animal Experiments Committee of Wageningen University.

\subsection{Extraction of endocannabinoids/NAEs from plasma}

Plasma $(100 \mu \mathrm{L})$ was thawed and $400 \mu \mathrm{L}$ extraction mixture containing $100 \mu \mathrm{M}$ PMSF and internal standards (AEA-d8, 2-AG-d8 and OEA-d4) in ACN was added while the sample was gently vortexed. After subsequent centrifugation ( $5 \mathrm{~min}$ at 13,000 rpm and RT), the supernatant was transferred to a clean Eppendorf tube and evaporated to dryness in a vacuum concentrator (Scanvac; Lynge, Denmark). The dried extracts were reconstituted in $100 \mu \mathrm{L}$ ACN containing $0.1 \%$ TFA and used for LC-MS/MS analysis.

\subsection{Extraction of endocannabinoids/NAEs from tissues}

Endocannabinoid/NAE were extracted from freeze-dried liver and ileum using a method adapted from a previously published protocol for plasma (Balvers et al. 2009). Approximately $50 \mathrm{mg}$ freeze-dried liver or $10 \mathrm{mg}$ freezedried ileum were extracted by adding $1 \mathrm{~mL}$ extraction mixture (ACN) and sonication. The samples were centrifuged ( $5 \mathrm{~min}$ at $14,000 \mathrm{rpm}$ ), the supernatant was transferred to a clean $15 \mathrm{~mL}$ tube, and this was repeated once. The pooled ACN fractions were diluted with MQ water containing $0.13 \%$ TFA until the final ACN concentration was $20 \%$ prior to SPE clean-up as described before (Balvers et al. 2009). In short, columns were washed with $20 \% \mathrm{v} / \mathrm{v}$ ACN in MQ water containing $0.1 \%$ TFA, eluted with $80 \% \mathrm{v} / \mathrm{v}$ ACN in MQ water containing $0.1 \% \mathrm{TFA}$ and evaporated to dryness using vacuum centrifugation. The dried extracts were reconstituted in $100 \mu \mathrm{L}$ ACN containing $0.1 \%$ TFA and used for LC-MS/MS analysis.

For adipose tissue, approximately $100 \mathrm{mg}$ 'wet' tissue was extracted with $1 \mathrm{~mL}$ extraction solution (ACN) by sonication. The samples were centrifuged for $5 \mathrm{~min}$ at $14,000 \mathrm{rpm}$ and RT, the supernatant was transferred to a clean $2.0 \mathrm{~mL}$ Eppendorf tube, and the ACN extraction was repeated once. The $2 \mathrm{~mL}$ ACN extract was subsequently evaporated to dryness, reconstituted in $100 \mu \mathrm{L}$ ACN containing $0.1 \%$ TFA and used for LC-MS/MS analysis.

\subsection{LC-MS/MS analysis of endocannabinoids/NAEs}

Two LC-MS/MS systems were used for endocannabinoid/ NAE analysis. Plasma extracts were analyzed by UPLC coupled to a Xevo TQ-S mass spectrometer (Waters; EttenLeur, The Netherlands) because high sensitivity was essential for adequate quantification in extracts obtained from 
$100 \mu \mathrm{L}$ plasma samples. Liver, ileum and adipose tissue were analyzed on a Surveyor HPLC coupled to a TSQ Quantum Discovery mass spectrometer (Thermo Finnigan; Breda, The Netherlands).

For the UPLC-Xevo system, $3 \mu \mathrm{L}$ plasma extract was injected on a Acquity C8 BEH UPLC column $(2.1 \times 100 \mathrm{~mm}$, $1.7 \mu \mathrm{m}$ ) and was separated using gradient elution with a stable flow of $500 \mu \mathrm{L} / \mathrm{min}$. The gradient started with $100 \%$ A (40:40:20 v/v/v of MQ water:methanol:ACN with $0.1 \% \mathrm{FA}$ ) which was maintained until $0.35 \mathrm{~min}$, followed by a linear increase to $100 \% \mathrm{~B}(7: 3 \mathrm{v} / \mathrm{v}$ methanol:ACN with $0.1 \% \mathrm{FA})$ which was achieved at $7.0 \mathrm{~min}$ and was maintained until $9.0 \mathrm{~min}$. Finally, the column equilibrated for $3 \mathrm{~min}$ at $100 \%$ A. The column was maintained at $60{ }^{\circ} \mathrm{C}$ during analysis, and the samples were kept at $10^{\circ} \mathrm{C}$. The MS was operating in selective reaction mode using electrospray ionization in positive ion mode, with a capillary voltage of $1.5 \mathrm{kV}$, a source temperature of $150{ }^{\circ} \mathrm{C}$ and a desolvation temperature of $500{ }^{\circ} \mathrm{C}$. Cone voltage and collision energy were optimized for each compound individually (see supplemental data S-1 for parent and product $\mathrm{m} / \mathrm{z}$ values). Peak identification and quantification was performed using MassLynx software version 4.1. Calibration curves were run in duplicate from which one regression equation was generated.

For the analysis of liver, ileum and adipose tissue, a TSQ Quantum Discovery was used as described before (Balvers et al. 2009). Five microliters extract was separated on an Xterra C8 MS column $(2.1 \times 150 \mathrm{~mm}, 3.5 \mu \mathrm{m})$ using gradient elution with a constant flow of $150 \mu \mathrm{L} / \mathrm{min}$. The same solutions were used as in the Xevo system, but now $1 \mathrm{~g} / \mathrm{L}$ ammonium acetate was added (the most dominant parent for 2-AG in this MS is the ammonium adduct). The gradient started with $100 \%$ A which was maintained until $2.0 \mathrm{~min}$, followed by a linear increase to $100 \% \mathrm{~B}$ which was achieved at $8.00 \mathrm{~min}$ and maintained until $16.0 \mathrm{~min}$, and the column was left to equilibrate for $5 \mathrm{~min}$ at $100 \%$ A. The column was maintained at $40{ }^{\circ} \mathrm{C}$ during analysis and the samples were cooled at $4{ }^{\circ} \mathrm{C}$. The MS was operating in selective reaction mode using electrospray ionization in positive ion mode, with a capillary voltage of $4.5 \mathrm{kV}$ and a capillary temperature of $350{ }^{\circ} \mathrm{C}$. Cone voltage and collision energy were optimized for each compound individually. Peak identification and quantification was performed using LCquan software version 2.5.5. Calibration curves were run in duplicate from which one regression equation was generated. Quality control samples were included in each analytical run to check the quality of the analysis and to correct for accuracy.

\subsection{Extraction of oxylipins from plasma}

Internal standards were added to the plasma samples which were already precipitated with methanol (see section ' 2.2 '), and the samples were put on ice for $30 \mathrm{~min}$. Samples were subsequently centrifuged $\left(5 \mathrm{~min}\right.$ at $3,000 \times g$ and $4^{\circ} \mathrm{C}$ ) and the supernatant was transferred to a glass tube. Just before loading on activated HLB columns, $4.75 \mathrm{~mL}$ MQ water containing $0.1 \% \mathrm{v} / \mathrm{v}$ FA was added to the methanol extract, diluting the extract to $20 \%$ methanol. After loading, the columns were washed with $2 \mathrm{~mL} 20 \%$ methanol in MQ water containing $0.1 \% \mathrm{FA}$, and the columns were allowed to dry for $15 \mathrm{~min}$. The SPE columns were eluted with $2 \mathrm{~mL}$ methanol and the samples were captured in tubes already containing $20 \mu \mathrm{L}$ of $10 \%$ glycerol and $500 \mu \mathrm{M}$ BHT in ethanol. The tubes were placed in a water bath at $40{ }^{\circ} \mathrm{C}$ and the methanol was evaporated under a gentle stream of nitrogen, after which the samples were reconstituted in $100 \mu \mathrm{L}$ ethanol containing another internal standard (CUDA) and immediately used for LC-MS/MS analysis.

\subsection{Extraction of oxylipins from tissues}

The extraction of oxylipins from liver, ileum and adipose tissue was similar to plasma oxylipin extraction. Approximately $100 \mathrm{mg}$ liver and adipose tissue, and $50 \mathrm{mg}$ ileum was extracted with $1 \mathrm{~mL}$ methanol containing internal standards and sonication. After centrifugation $(5 \mathrm{~min}$ at $3,000 \times g$ and $4{ }^{\circ} \mathrm{C}$ ), the supernatants were transferred to clean tubes and the methanol extraction was repeated once. Just before loading on HLB SPE columns, $8 \mathrm{~mL}$ MQ water containing $0.1 \%$ FA was added to the methanol extracts. For the SPE procedure and further, (see section '2.6') Extraction of oxylipins from plasma'.

\subsection{LC-MS/MS analysis of oxylipins}

All oxylipin analyses were performed on a UPLC coupled to a Xevo TQ-S mass spectrometer (Waters). Five microliters extract was injected on a Acquity C18 BEH UPLC column $(2.1 \times 100 \mathrm{~mm}, 1.7 \mu \mathrm{m})$ and was separated using gradient elution with a stable flow of $600 \mu \mathrm{L} / \mathrm{min}$. The gradient started with $95 \%$ A (MQ water with $0.1 \% \mathrm{FA}$ ) and $5 \% \mathrm{~B}$ (ACN with $0.1 \% \mathrm{FA}$ ) followed by a linear increase to $70 \% \mathrm{~A}$ and $30 \% \mathrm{~B}$ which was achieved at $5.0 \mathrm{~min}$. This was followed by a linear increase towards $50 \% \mathrm{~B}$ which was achieved at $11.25 \mathrm{~min}$ and maintained until $13.25 \mathrm{~min}$. The system was subsequently switched to $100 \% \mathrm{~B}$, which was achieved at $15.75 \mathrm{~min}$ and maintained until $16.75 \mathrm{~min}$, after which the column was left to equilibrate at $5 \% \mathrm{~B}$ for approximately $3 \mathrm{~min}$. The column was maintained at $50{ }^{\circ} \mathrm{C}$ during analysis, and the samples were kept at $10{ }^{\circ} \mathrm{C}$. The MS was operating in selective reaction mode using electrospray ionization in negative ion mode, with a capillary voltage of $3.3 \mathrm{kV}$, a source temperature of $150{ }^{\circ} \mathrm{C}$ and a desolvation temperature of $600{ }^{\circ} \mathrm{C}$. Cone voltage and collision energy were optimized for each 
compound individually (see supplemental data $\mathrm{S}-1$ for parent and product $\mathrm{m} / \mathrm{z}$ values). Peak identification and quantification was performed using MassLynx software version 4.1. Calibration curves were run in duplicate from which one regression equation was generated. During data analysis, five peaks of unknown identity were found to be influenced by diet or LPS treatment, and these compounds are listed UK1-UK5. These peaks were visible in the transitions $\mathrm{m} / \mathrm{z} \quad 295.2>195.2$ and $\mathrm{m} / \mathrm{z} \quad 295.2>171.1$. ARA, DHA and EPA were also determined using this method. Quality control samples were included in each analytical run to check the quality of the analysis and to correct for accuracy.

\subsection{Data analysis}

Univariate analysis was performed with SAS version 9.1 (2002-2003 by SAS Institute Inc., Cary, NC, USA). ANOVA assumptions were checked for each variable. If these assumptions were not met, rank transformation was applied for that particular variable. Partial tests were performed using Tukey-Kramer multiple comparison correction. Benjamini and Hochberg false discovery rate correction $(q=5 \%)$ was applied to correct for false positives (Benjamini and Hochberg 1995). In all statistical tests that were performed, the null hypothesis (no effect) was rejected at the 0.05 level of probability $(\alpha=5 \%)$.

The added value of multivariate data analysis in addition to univariate statistics is that correlations between variables are taken into account, and thus also allows to reveal combinations of variables which are associated with differences between treatment groups. Multivariate data analysis summarizes all the variables into one variable by means of a linear combination, now called the 'principal component' (PC), which adds higher weights to variables that account for the highest level of variance in the original data. Using principal component analysis (PCA), we screened for group separation, outliers, (undesired) patterns and this was further analyzed with principal component discriminant analysis (PCDA). PCDA includes the original group designation of the animals in the model and is therefore called a supervised classification technique. PCA and PCDA were performed in the Matlab environment (R2008b, 1984-2008, The Mathworks Inc., Natick, MA, USA) using the PLS toolbox for Matlab version 5.0.3 (r 6466, 1995-2008, Eigenvector Research Inc., Wenatchee, WA, USA). PCA and PCDA are described in more detail elsewhere (Hoogerbrugge et al. 1983; Joliffe 1986). For all multivariate models data were autoscaled to mean zero and variance 1 for each variable. For PCDA, stability of the model was evaluated by 10 -fold cross-validation, revealing correct classification rates of typically $80-100 \%$. PCA and PCDA were performed on the combined data ('fused data'), containing data on both endocannabinoids/NAEs and oxylipins from plasma, liver ileum and adipose tissue combined in one data set.

\section{Results}

3.1 FO diet and inflammation alter the endocannabinoid/NAE balance

To investigate the effect of dietary n-3 fatty acids and inflammation on endocannabinoid/NAE and oxylipin levels, wild-type male C57BL/6 mice received a diet containing either no, 1 or $3 \% \mathrm{w} / \mathrm{w}$ FO followed by either saline or $2 \mathrm{mg} / \mathrm{kg}$ LPS i.p. injection. Endocannabinoid/ NAE levels were determined in plasma, liver, ileum and adipose tissue.

Detailed (quantitative) effects of dietary administration of fish-oil and administering LPS after 6 weeks compared to their relevant control treatments are provided in the supplemental data (S2-7), including some representative chromatograms (S-8). Significant differences between diet groups and LPS treatment were obtained with the ANOVA test and are summarized in Tables 1, 2 for endocannabinoids/NAEs and Tables 3, 4 for oxylipins. A diet effect is here defined as an effect of the diet which (in magnitude and direction) was the same for saline and LPS-treated mice. The term LPS effect refers to situations in which LPS induced a change in a concentration of a compound, which was similar for all diet groups. An interaction effect indicates that only certain (combinations of) diets with saline or LPS resulted in significant differences, and therefore separate comparisons ('partial tests') should be interpreted rather than main effects. Table 1 shows diet effects on NAEs/endocannabinoids, and 2 LPS effects. Compounds with an interaction effect are highlighted with $*$ in the tables, with further details provided in the supplemental data (S-5).

The FO diets altered endocannabinoid levels with different effects in plasma, liver, ileum and adipose tissue (Table 1). DHEA was increased by both FO diets in all compartments compared to control diet. For EPEA, an interaction effect (see supplemental data) was observed in liver, but the compound was increased by the FO diets in plasma, ileum and adipose tissue. The endocannabinoids/ NAEs derived from other fatty acids, such as AEA and 2-AG, were in general decreased by the FO diets, but some deviations were observed. For instance, 2-AG levels in adipose tissue and liver were decreased in both FO groups compared to the control diet. When comparing the $1 \%$ versus the $3 \%$ FO group, liver 2-AG was lower in the $3 \%$ group, but higher in adipose tissue. DGLEA (also known as DLE) in liver was not influenced by the diets, but was 
Table 1 Effect of the fish oil diets on endocannabinoid/NAE levels in plasma, liver, ileum and adipose tissue (diet effect)

\begin{tabular}{|c|c|c|c|c|c|c|}
\hline & & & Plasma & Liver & Ileum & Adi. tiss. \\
\hline \multirow[t]{6}{*}{ Ctrl vs $1 \%$ FO } & \multirow[t]{2}{*}{$\mathrm{n}-3$ derived } & EPEA & 2.51 & $*$ & 24.159 & 43.096 \\
\hline & & DHEA & 1.915 & 2.908 & 2.123 & 3.241 \\
\hline & \multirow[t]{4}{*}{ Other } & AEA & $*$ & 0.312 & 0.374 & 0.350 \\
\hline & & $2-\mathrm{AG}$ & 0.403 & 0.216 & 0.304 & 0.465 \\
\hline & & DGLEA & 0.282 & - & 0.650 & 0.562 \\
\hline & & OEA & 0.710 & 0.777 & - & $*$ \\
\hline \multirow[t]{7}{*}{ Ctrl vs $3 \%$ FO } & \multirow[t]{2}{*}{$\mathrm{n}-3$ derived } & EPEA & 3.688 & $*$ & 67.069 & 116.975 \\
\hline & & DHEA & 2.166 & 4.691 & 2.774 & 5.484 \\
\hline & \multirow[t]{5}{*}{ Other } & AEA & $*$ & - & 0.811 & 0.423 \\
\hline & & $2-A G$ & 0.301 & 0.156 & 0.272 & 0.607 \\
\hline & & DGLEA & 0.250 & - & $\downarrow$ & 0.578 \\
\hline & & OEA & 0.522 & 0.663 & - & $*$ \\
\hline & & SEA & 0.692 & - & - & 1.574 \\
\hline \multirow[t]{5}{*}{$1 \% \mathrm{FO}$ vs $3 \% \mathrm{FO}$} & \multirow[t]{2}{*}{$\mathrm{n}-3$ derived } & EPEA & - & $*$ & 2.776 & 2.714 \\
\hline & & DHEA & - & 1.613 & 1.306 & 1.692 \\
\hline & \multirow[t]{3}{*}{ Other } & $2-A G$ & - & 0.724 & - & 1.304 \\
\hline & & OEA & 0.735 & - & - & $*$ \\
\hline & & SEA & 0.700 & - & - & 1.284 \\
\hline
\end{tabular}

Only statistically significant effects are listed, presented as fold-control values, calculated by comparing mean metabolite concentration from one diet to another. Means were calculated from saline and LPS treated animals together per diet group. $\uparrow$ or $\downarrow$ were used when the fold-control value would disagree with the outcome outcome of the ANOVA in cases of variables which were rank-transformed

$N D$ the compound was not detected in the particular matrix, and - indicates that no statistical significant differences were observed

* Interaction effect (see supplemental data for details)

Table 2 Effect of LPS on endocannabinoid/NAE levels in plasma, liver, ileum and adipose tissue (LPS effect)

\begin{tabular}{|c|c|c|c|c|c|c|}
\hline & & & Plasma & Liver & Ileum & Adi. tiss. \\
\hline \multirow[t]{8}{*}{ Saline vs LPS } & \multirow[t]{2}{*}{$\mathrm{n}-3$ derived } & EPEA & 2.019 & $*$ & - & 1.766 \\
\hline & & DHEA & 2.101 & 4.130 & 1.338 & 1.584 \\
\hline & \multirow[t]{6}{*}{ Other } & AEA & $*$ & 3.375 & 1.274 & - \\
\hline & & $2-\mathrm{AG}$ & 0.651 & - & - & 1.366 \\
\hline & & DGLEA & 1.961 & 1.611 & $\uparrow$ & - \\
\hline & & PEA & $*$ & 0.743 & 1.406 & $*$ \\
\hline & & OEA & 3.097 & 2.276 & 1.260 & $*$ \\
\hline & & SEA & 2.073 & 0.540 & 1.676 & 0.711 \\
\hline
\end{tabular}

Only statistically significant effects are listed, presented as fold-control values, calculated by comparing mean metabolite concentration from the saline to the LPS treated groups. Means were calculated from the different diet groups together for the saline and LPS treated animals. $\uparrow$ or $\downarrow$ were used when the fold-control value would disagree with the outcome outcome of the ANOVA in cases of variables which were ranktransformed

$N D$ the compound was not detected in the particular matrix, and - no statistical significant differences were observed

* Interaction effect (see supplemental data for details)

decreased in plasma, ileum and adipose tissue in the FO groups. OEA was decreased in liver and plasma, but not in ileum. When comparing the control diet group with the $3 \%$ FO group, SEA displayed opposite effects in adipose tissue and plasma; FO was found to decrease plasma levels, but increased adipose tissue levels of SEA. This was also observed when comparing the $1 \%$ versus the $3 \% \mathrm{FO}$ groups.
The effect of LPS on endocannabinoids appeared to be both compound and tissue specific (Table 2; for effects of LPS on endocannabinoids for each diet group, please refer to the supplemental data). LPS increased DHEA levels in all compartments, but for some compounds tissue-specific effects were seen. LPS decreased plasma 2-AG, whereas it increased adipose tissue 2-AG. A similar divergence is seen for SEA and PEA. LPS increased plasma and ileum 
Table 3 Effect of the fish oil diets on oxylipin levels in plasma, liver, ileum and adipose tissue (diet effect)

\begin{tabular}{|c|c|c|c|c|}
\hline & Plasma & Liver & Ileum & Adi. tiss. \\
\hline \multicolumn{5}{|l|}{ Ctrl vs $1 \%$ FO } \\
\hline \multicolumn{5}{|l|}{ Fatty acids } \\
\hline ARA & $*$ & 0.326 & - & 0.520 \\
\hline DHA & 1.931 & - & 2.128 & - \\
\hline EPA & * & 13.93 & 24.182 & 29.425 \\
\hline \multicolumn{5}{|l|}{ n-3 derived oxylipins } \\
\hline 5-HEPE & 4.358 & 7.474 & 9.459 & 34.105 \\
\hline 12-HEPE & $*$ & 4.753 & 19.379 & 24.735 \\
\hline $\mathrm{PGD}_{3}$ & ND & ND & 18.828 & 3.937 \\
\hline $\mathrm{PGE}_{3}$ & - & ND & 15.534 & 12.614 \\
\hline 17-HDoHE & - & - & 3.014 & 2.694 \\
\hline 10-17-DiHDoHE & ND & ND & 2.566 & 3.352 \\
\hline 19,20-DiHoPE & 3.040 & 1.534 & 2.381 & 4.447 \\
\hline $\mathrm{TBXB}_{3}$ & $*$ & ND & 20.657 & 4.809 \\
\hline \multicolumn{5}{|l|}{ n-6 oxylipins } \\
\hline 5,6 EET & - & 0.163 & - & - \\
\hline $11,12 \mathrm{EET}$ & - & 0.293 & 0.495 & 0.484 \\
\hline 14,15 EET & 0.492 & 0.319 & 0.476 & 0.497 \\
\hline $\mathrm{LTB}_{4}$ & ND & 3.356 & 0.470 & $*$ \\
\hline $\mathrm{LTD}_{4}$ & ND & ND & 0.184 & - \\
\hline 5,6-DiHETrE & - & 0.215 & 0.392 & 0.383 \\
\hline 8,9-DiHETrE & 0.314 & 0.213 & 0.378 & $*$ \\
\hline 11,12-DiHETrE & 0.280 & 0.249 & 0.419 & 0.378 \\
\hline 14,15-DiHETrE & 0.327 & 0.251 & 0.404 & $*$ \\
\hline $\mathrm{PGE}_{2}$ & - & 0.205 & - & - \\
\hline $\mathrm{PGF}_{2 \alpha}$ & - & 0.234 & - & - \\
\hline 8-iso-PGF $2 \alpha$ & - & - & - & 0.629 \\
\hline 13,14-dihydro-15-keto- $\mathrm{PGD}_{2}$ & ND & ND & 0.292 & ND \\
\hline 13,14-dihydro-15-keto-PGE 2 & $\downarrow$ & 0.373 & 0.242 & 0.198 \\
\hline 13,14-dihydro-15-keto-PGF ${ }_{2 \alpha}$ & ND & 0.432 & 0.255 & 0.473 \\
\hline 12-HHTrE & - & 0.107 & - & 0.298 \\
\hline 5-HETE & 0.416 & 0.410 & - & 0.632 \\
\hline 11-HETE & - & 0.233 & - & 0.417 \\
\hline 12-HETE & - & 0.150 & - & - \\
\hline 15-HETE & - & 0.211 & - & 0.252 \\
\hline 20-HETE & ND & 0.419 & - & ND \\
\hline $\mathrm{TBXB}_{2}$ & - & 0.209 & - & - \\
\hline 13-HODE & - & 0.570 & - & - \\
\hline 9,10,13-TriHOME & - & $*$ & - & 0.686 \\
\hline \multicolumn{5}{|l|}{ Ctrl vs $3 \% \mathrm{FO}$} \\
\hline \multicolumn{5}{|l|}{ Fatty acids } \\
\hline ARA & $*$ & 0.302 & - & - \\
\hline DHA & 1.642 & - & 2.828 & - \\
\hline EPA & $*$ & 19.597 & 37.806 & 54.972 \\
\hline $\begin{array}{l}17 \text { keto- 4(z), 7(z), 10(z), } \\
13 \text { (z), } 15 \text { (E), 19(z)-DHA }\end{array}$ & ND & - & 2.830 & * \\
\hline \multicolumn{5}{|l|}{ n-3 derived oxylipins } \\
\hline 5-HEPE & 7.430 & 12.323 & 19.378 & 163.982 \\
\hline 12-HEPE & $*$ & 7.684 & 33.107 & 55.445 \\
\hline $\mathrm{PGD}_{3}$ & ND & ND & 14.818 & 9.352 \\
\hline $\mathrm{PGE}_{3}$ & - & ND & 23.562 & 32.107 \\
\hline 17-HDoHE & - & 2.051 & 3.362 & 3.148 \\
\hline 10-17-DiHDoHE & ND & ND & 3.384 & 4.768 \\
\hline 19,20-DiHoPE & 5.717 & 2.244 & 4.172 & 18.053 \\
\hline $\mathrm{TBXB}_{3}$ & $*$ & ND & 16.198 & 10.438 \\
\hline
\end{tabular}


Table 3 continued
Only statistically significant effects are listed, presented as fold-control values, calculated by comparing mean metabolite concentration from one

diet to another. Means were calculated from saline and LPS treated animals together per diet group. $\uparrow$ or $\downarrow$ were used when the fold-control value would disagree with the outcome outcome of the ANOVA in cases of variables which were rank-transformed

$N D$ the compound was not detected in the particular matrix, and '-' indicates that no statistical significant differences were observed

* Interaction effect (see supplemental data for details)

\begin{tabular}{|c|c|c|c|c|}
\hline & Plasma & Liver & Ileum & Adi. tiss. \\
\hline \multicolumn{5}{|l|}{ Other oxylipins } \\
\hline $5,6 \mathrm{EET}$ & - & 0.120 & - & - \\
\hline 8,9 EET & ND & ND & 0.329 & - \\
\hline $11,12 \mathrm{EET}$ & 0.512 & 0.179 & 0.489 & 0.566 \\
\hline $14,15 \mathrm{EET}$ & 0.492 & 0.277 & 0.537 & - \\
\hline $\mathrm{LTB}_{4}$ & $\mathrm{ND}$ & 3.524 & 0.357 & $*$ \\
\hline $\mathrm{LTD}_{4}$ & ND & ND & 0.184 & - \\
\hline n-acetyl-leukotriene $\mathrm{E}_{4}$ & ND & 0.628 & $*$ & ND \\
\hline 5,6-DiHETrE & 0.358 & - & 0.246 & 0.496 \\
\hline 8,9-DiHETrE & 0.481 & 0.186 & 0.328 & $*$ \\
\hline 11,12-DiHETrE & 0.303 & 0.221 & 0.388 & 0.593 \\
\hline 14,15-DiHETrE & 0.562 & 0.224 & 0.366 & $*$ \\
\hline $\mathrm{PGD}_{2}$ & 0.363 & $*$ & - & - \\
\hline $\mathrm{PGE}_{2}$ & 0.397 & 0.229 & - & - \\
\hline $\mathrm{PGF}_{2 \alpha}$ & - & 0.259 & - & - \\
\hline 8-iso-PGF $2 \alpha$ & - & - & - & 0.623 \\
\hline 13,14-dihydro-15-keto-PGD 2 & ND & ND & 0.180 & ND \\
\hline 13,14-dihydro-15-keto- $\mathrm{PGE}_{2}$ & 0.479 & 0.275 & 0.157 & 0.244 \\
\hline 13,14-dihydro-15-keto- $\mathrm{PGF}_{2 \alpha}$ & ND & 0.240 & 0.200 & 0.405 \\
\hline 12-HHTrE & 0.421 & 0.094 & - & 0.224 \\
\hline 5-HETE & 0.375 & - & - & - \\
\hline 11-HETE & 0.401 & 0.094 & - & - \\
\hline 12-HETE & 0.265 & 0.159 & - & 0.289 \\
\hline 15-HETE & 0.323 & 0.250 & - & 0.234 \\
\hline 20-HETE & ND & 0.447 & - & ND \\
\hline $\mathrm{TBXB}_{2}$ & 0.403 & 0.215 & - & - \\
\hline 9-HODE & - & - & - & 0.417 \\
\hline 13-HODE & 0.559 & $\downarrow$ & - & 0.308 \\
\hline lipoxin $\mathrm{A}_{4}$ & ND & 1.771 & 2.533 & 7.181 \\
\hline \multicolumn{5}{|l|}{$1 \% \mathrm{FO}$ vs $3 \% \mathrm{FO}$} \\
\hline \multicolumn{5}{|l|}{ Fatty acids } \\
\hline DHA & - & - & 1.329 & - \\
\hline EPA & $*$ & - & 1.563 & 1.868 \\
\hline $\begin{array}{l}17 \text { keto- } 4(\mathrm{z}), 7(\mathrm{z}), 10(\mathrm{z}) \\
13(\mathrm{z}), 15(\mathrm{E}), 19(\mathrm{z}) \text {-DHA }\end{array}$ & ND & - & 1.786 & $*$ \\
\hline \multicolumn{5}{|l|}{$\mathrm{n}-3$ derived oxylipins } \\
\hline 5-HEPE & - & 1.649 & 2.049 & 4.808 \\
\hline 12-HEPE & $*$ & - & 1.708 & 2.242 \\
\hline $\mathrm{PGD}_{3}$ & ND & ND & - & 2.545 \\
\hline $\mathrm{PGE}_{3}$ & - & ND & - & 2.375 \\
\hline 17-HDoHE & - & 1.435 & - & - \\
\hline 19,20-DiHoPE & - & 1.463 & - & 4.060 \\
\hline \multicolumn{5}{|l|}{ Other oxylipins } \\
\hline 5-HETE & - & - & 0.416 & 1.739 \\
\hline 11-HETE & 0.487 & - & - & - \\
\hline 13-HODE & 0.651 & - & - & - \\
\hline 15-HETE & 0.442 & - & - & - \\
\hline $\mathrm{PGE}_{2}$ & 0.492 & - & - & - \\
\hline 13,14-dihydro-15-keto- $\mathrm{PGE}_{2}$ & - & - & 0.648 & - \\
\hline 13,14-dihydro-15-keto- $\mathrm{PGF}_{2 \alpha}$ & ND & 0.555 & - & - \\
\hline lipoxin $\mathrm{A}_{4}$ & ND & 2.075 & 2.877 & 6.588 \\
\hline
\end{tabular}


Table 4 Effect of LPS on oxylipin levels in plasma, liver, ileum and adipose tissue (LPS effect)

\begin{tabular}{|c|c|c|c|c|c|c|}
\hline & & & Plasma & Liver & Ileum & Adi. tiss. \\
\hline \multirow[t]{35}{*}{ Saline vs LPS } & \multirow[t]{3}{*}{ Fatty acids } & ARA & $*$ & 1.827 & - & 1.854 \\
\hline & & DHA & 2.033 & 1.590 & - & - \\
\hline & & EPA & $*$ & - & - & 1.791 \\
\hline & \multirow[t]{6}{*}{$\mathrm{n}-3$ derived oxylipins } & 5-HEPE & 2.049 & - & - & 5.626 \\
\hline & & $\mathrm{PGD}_{3}$ & ND & ND & - & 2.498 \\
\hline & & $\mathrm{PGE}_{3}$ & - & ND & 3.256 & 4.217 \\
\hline & & 10(S)-17(S)-DiHDoHE & ND & ND & - & 2.249 \\
\hline & & 19,20-DiHoPE & 3.886 & 1.376 & 1.874 & 3.822 \\
\hline & & $\mathrm{TBXB}_{3}$ & $*$ & ND & 2.637 & 4.752 \\
\hline & \multirow[t]{26}{*}{ Other oxylipins } & 5,6 EET & - & - & - & 2.847 \\
\hline & & $11,12 \mathrm{EET}$ & - & - & - & 1.843 \\
\hline & & $14,15 \mathrm{EET}$ & - & 1.890 & - & - \\
\hline & & $\mathrm{LTB}_{4}$ & ND & 0.538 & - & $*$ \\
\hline & & $\mathrm{LTD}_{4}$ & ND & ND & - & 2.445 \\
\hline & & n-acetyl leukotriene $E_{4}$ & ND & 1.627 & $*$ & ND \\
\hline & & 5,6 DiHETrE & - & - & - & 1.744 \\
\hline & & 8,9-DiHETrE & 2.170 & - & - & $*$ \\
\hline & & 11,12-DiHETrE & 2.167 & - & - & - \\
\hline & & 14,15-DiHETrE & 1.943 & - & - & $*$ \\
\hline & & $\mathrm{PGE}_{2}$ & 1.958 & 2.449 & - & 2.039 \\
\hline & & $\mathrm{PGF}_{2 \alpha}$ & - & - & - & 1.777 \\
\hline & & 8 -iso-PGF $2 \alpha$ & - & 1.778 & - & - \\
\hline & & 13,14-dihydro-15-keto- $\mathrm{PGE}_{2}$ & 2.600 & - & - & 1.243 \\
\hline & & 13,14 -dihydro-15-keto- $\mathrm{PGF}_{2 \alpha}$ & ND & 1.815 & - & - \\
\hline & & 12-HHTrE & 0.201 & - & - & 2.252 \\
\hline & & 5-HETE & 2.240 & - & - & 2.435 \\
\hline & & 11-HETE & 0.561 & 1.887 & - & 1.925 \\
\hline & & 12-HETE & - & 0.782 & - & - \\
\hline & & 15-HETE & 0.433 & - & - & - \\
\hline & & 20-HETE & ND & 2.399 & - & ND \\
\hline & & $\mathrm{TBXB}_{2}$ & 0.175 & - & 2.560 & 2.277 \\
\hline & & 9-HODE & 1.267 & - & 2.768 & 2.014 \\
\hline & & 13-HODE & - & - & 2.086 & 1.206 \\
\hline & & 9,10,13-TriHOME & 1.301 & $*$ & - & - \\
\hline & & Lipoxin $\mathrm{A}_{4}$ & ND & - & - & 2.372 \\
\hline
\end{tabular}

Only statistically significant effects are listed, presented as fold-control values, calculated by comparing mean metabolite concentration from the saline to the LPS groups. Means were calculated from the different diet groups together for saline and LPS treated animals.

$N D$ the compound was not detected in the particular matrix, and - indicates that no statistical significant differences were observed

* Interaction effect (see supplemental data for details)

SEA levels, but decreases liver and adipose tissue SEA levels. PEA levels were decreased in liver by LPS, but increased in ileum.

In summary, both the FO diets and the LPS treatment affected plasma and tissue endocannabinoid/NAE levels. In general, DHEA and EPEA were increased by the FO diets, and compounds derived from other fatty acids were decreased, with different effects for 1 and $3 \%$ FO diets.
LPS raised endocannabinoid/NAE levels in general, but opposing effects were seen for 2-AG, PEA and SEA across the tissues investigated.

\subsection{FO diet and inflammation alter the oxylipin balance}

The results of the oxylipin analyses in plasma, liver, ileum and adipose tissue are presented in Tables 3 and 4, with 
Table 5 Top lists generated from PCA analysis

\begin{tabular}{|c|c|c|c|}
\hline & PC1 & & $\mathrm{PC} 2$ \\
\hline P_AEA & 0.13562 & F_pea & 0.148486 \\
\hline P_AA & 0.128696 & L_dhea & 0.141097 \\
\hline P_DLE & 0.12706 & F_TBXB3 & 0.138751 \\
\hline L_13,14-dihydro-15-keto-PGF2a & 0.120315 & P_DHEA & 0.137637 \\
\hline L_AA & 0.12015 & P_19,20-DiHoPE & 0.137193 \\
\hline L_2-ag & 0.116734 & F_UK3 & 0.136532 \\
\hline P_11,12-DiHETrE & 0.116219 & F_5(S)-HETE & 0.136382 \\
\hline L_8,9-DiHETrE & 0.115152 & F_17 keto- 4(z), 7(z), 10(z), $13(\mathrm{z}), 15(\mathrm{E}), 19(\mathrm{z})$-DHA & 0.135592 \\
\hline I_13,14-dihydro-15-keto-PGE2 & 0.114106 & F_PGE3 & 0.133149 \\
\hline I_2-ag & 0.113331 & F_19,20-DiHoPE & 0.133074 \\
\hline L_15(S)-HETE & 0.112971 & F_oea & 0.132124 \\
\hline F_aea & 0.112488 & F_UK5 & 0.131976 \\
\hline L_EPA & -0.11245 & F_UK2 & 0.128994 \\
\hline L_14,15 EET & 0.111192 & I_PGE3 & 0.128277 \\
\hline L_5(S)-HEPE & -0.11066 & F_UK4 & 0.127957 \\
\hline L_11(S)-HETE & 0.10907 & P_DHA & 0.127188 \\
\hline P_14,15-DiHETrE & 0.107335 & F_AA & 0.125684 \\
\hline I_13,14-dihydro-15-keto-PGF2a & 0.105203 & F_5(S)-HEPE & 0.12297 \\
\hline P_8,9-DiHETrE & 0.104781 & I_19,20-DiHoPE & 0.121367 \\
\hline L_11,12 EET & 0.103724 & F_12,13-DiHOME & 0.12071 \\
\hline I_13,14-dihydro-15-keto-PGD2 & 0.100174 & P_PEA & 0.120517 \\
\hline L_PGE2 & 0.100147 & P_12,13-DiHOME & 0.118135 \\
\hline I_12(S)-HEPE & -0.09961 & F_lipoxin A4 & 0.115389 \\
\hline F_2-ag & 0.099293 & P_EPEA & 0.115294 \\
\hline L_14,15-DiHETrE & 0.098683 & F_5,6 EET & 0.115132 \\
\hline L_12(S)-HHTrE & 0.098509 & F_PGD3 & 0.114641 \\
\hline I_EPA & -0.09806 & F_dhea & 0.113431 \\
\hline F_dle & 0.09791 & L_epea & 0.112967 \\
\hline F_13,14-dihydro-15-keto-PGF2a & 0.097779 & P_9,10-DiHOME & 0.11289 \\
\hline F_EPA & -0.09662 & F_9,10-DiHOME & 0.109149 \\
\hline
\end{tabular}

The D-scores represent the variable's weight in the separation, and is expressed as the numerical output value as obtained from the PCA model; the further away from zero, the better this variable accounts for group separation. PC1 separated the diets, whereas PC2 separated between saline and LPS treatment

$P$ plasma, $L$ liver, $I$ ileum, $F$ adipose tissue

Table 3 showing diet effects and Table 4 LPS effects. Compounds with an interaction effects are highlighted with an $*$ in the tables, with details provided in the supplemental data (S-5 and S-6). UK compounds are not presented in Table 5, but can be found in the supplemental data.

The FO diets decreased levels of ARA and increased DHA and EPA, confirming that the increased dietary intake of n-3 fatty acids was reflected in tissue fatty acid levels (Table 3). Furthermore, n-3 derived oxylipin levels were increased by the FO diets, with the most pronounced effects observed in ileum and adipose tissue. The oxylipins derived from other fatty acids were in general decreased by the FO diets, with some exceptions, and effects were not always consistent over all tissues tested. Levels of $\mathrm{LTB}_{4}$ were decreased in ileum and adipose tissue by the FO diets, but liver levels were increased. Lipoxin $\mathrm{A}_{4}$ levels were increased in the $3 \%$ FO group compared to the control and $1 \%$ FO diet in liver, ileum and adipose tissue. When comparing the 1 and $3 \%$ FO diets, ileal 5-HETE levels were decreased in the $3 \%$ FO group, but its level was increased in adipose tissue. The FO diets decreased oxylipins belonging to different branches of the fatty acid oxylipin cascade, including the cyclooxygenase pathway (COX; $\mathrm{PGD}_{2}$, PGE2 and their metabolites 13,14-dihydro-15keto- $\mathrm{PGD}_{2}$ and $-\mathrm{PGE}_{2}, \mathrm{PGF}_{2 \alpha}, \mathrm{TBXB}_{2}$ ), the 15-lipo-oxygenase pathway (15-LOX; 15-HETE), 12-LOX (11-HETE 
and 12-HETE), 5-LOX (5-HETE, $\mathrm{LTB}_{4}$ and $\mathrm{LTD}_{4}$ ) and the cytochrome P450 pathways (EETs and DiHETrEs) (see Fig. 1 for an overview).

Treatment with LPS generally resulted in increased levels of fatty acids, n-3 derived oxylipins and other oxylipins, with the most compounds affected in plasma and adipose tissue, and the least number of compounds altered in ileum (Table 4; for effects of LPS on oxylipins for each diet group, please refer to the supplemental data). Again, opposing effects were observed between compartments for some components. LPS decreased plasma levels of 11-HETE, but increased liver levels. $\mathrm{TBXB}_{2}$ was decreased by LPS in plasma, but increased in ileum and adipose tissue. Effects on UK compounds are listed in the supplemental data.

\subsection{Multivariate data analysis shows separation between diet groups and LPS treatment}

The univariate data analysis approach revealed that both FO and LPS altered endocannabinoid/NAE and oxylipin levels, and effects were seen in plasma, liver, ileum and adipose tissue. In total, 244 variables obtained in four compartments were evaluated, which were, due to complexity, further analyzed with multivariate data analysis to evaluate differences between treatment groups. Two methods were used, the unbiased PCA and the supervised PCDA. In the PCA plot (Fig. 2), a good separation of the six intervention groups can be seen. PC1 separated the diets, with negative loadings associated to $n-3$ fatty acid derived metabolites, and positive loadings belonging to other metabolites. From the top-30 variables relevant for

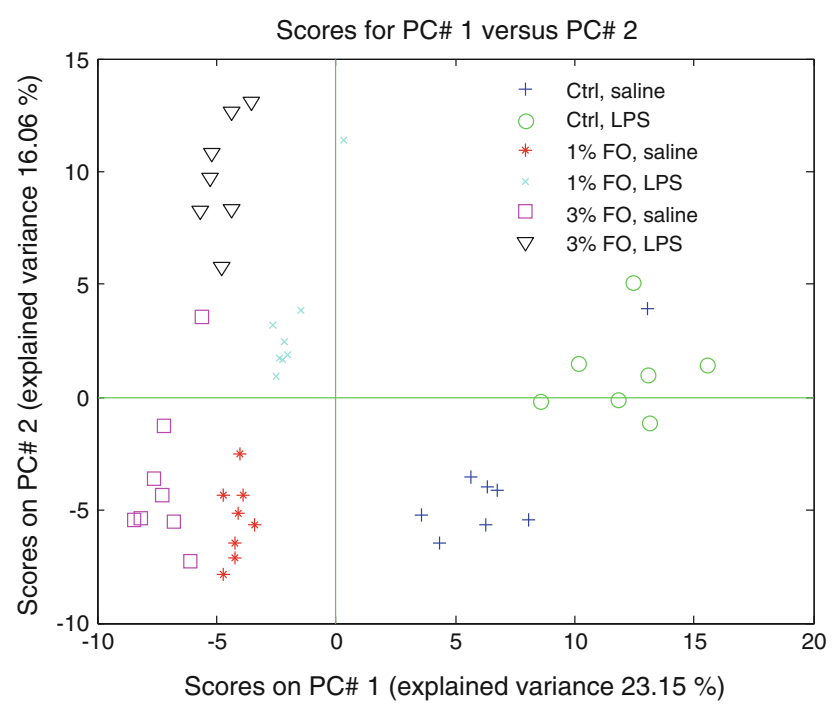

Fig. 2 PCA analysis on fused data. The PCA plot shows good separation of the three diet groups. PC1 describes mainly the diet effect, and PC2 mainly the LPS effect group separation in PC1 (see Table 5), 13 variables were from liver, whereas plasma, ileum and adipose tissue were equally important. In total four metabolites were derived from $n-3$ fatty acids, and 26 were derived from other fatty acids. PC2 separated between saline and LPS treatment, containing equal numbers of n-3 derived- and other metabolites. From the top-30 variables accounting in PC2, 19 metabolites were from adipose tissue, with 15 n-3 fatty acid derived metabolites, and 15 derived from other fatty acids.

3.4 The diet effect in the saline treated mice is explained by other variables than the diet effect in the LPS-treated mice

To further explore differences between diet groups, PCDA was performed. The data was split for saline and LPStreated mice, thus resulting in two separate PCDA plots. PCDA analyses showed that there is separation based on diet for both the saline and LPS-treated mice (Fig. 3). The contribution of a variable in the PCDA model is expressed as its D-score, with a positive score meaning an increase by the FO diets, and a negative score indicating a decrease. Analysis of D-scores focused on the 50 compounds with the highest D-scores as there was considerable decay in D-score values between the first and 50th compound, meaning that any differences within this range can be considered as a potentially meaningful difference. The analysis revealed that the diet groups are separated by increased levels of $n-3$ derived compounds in the FO groups, and compounds derived from other fatty acids were generally decreased by the FO diets (Table 6). In addition to this, both endocannabinoids/NAEs and oxylipins show up in the top of the rank lists, indicating that both classes of compounds are important to describe the diet effect. The ranking, number and origin of $n-3$ derived metabolites in the models is different between the saline and LPS treated animals. Out of the 50 compounds ranking highest for the saline treated mice, only 12 compounds are $n-3$ fatty acid derived metabolites, while for the LPS treated mice, the top-50 list contains 25 n-3 fatty acid derived metabolites. In addition to this, the majority of $\mathrm{n}-3$ derived compounds in the LPS treated mice from this list originated from adipose tissue.

From these results, it can be concluded that the diet effect of FO in the saline treated animals is mainly explained by a decrease of compounds derived from other than n-3 fatty acids, and to a lesser extent by an increase of n-3 derived metabolites. However, for the LPS treated mice, the diet effect is principally explained by an increase of n-3 derived metabolites, and to a lesser extent by a decrease of metabolites derived from other than $n-3$ fatty acids. 
Saline

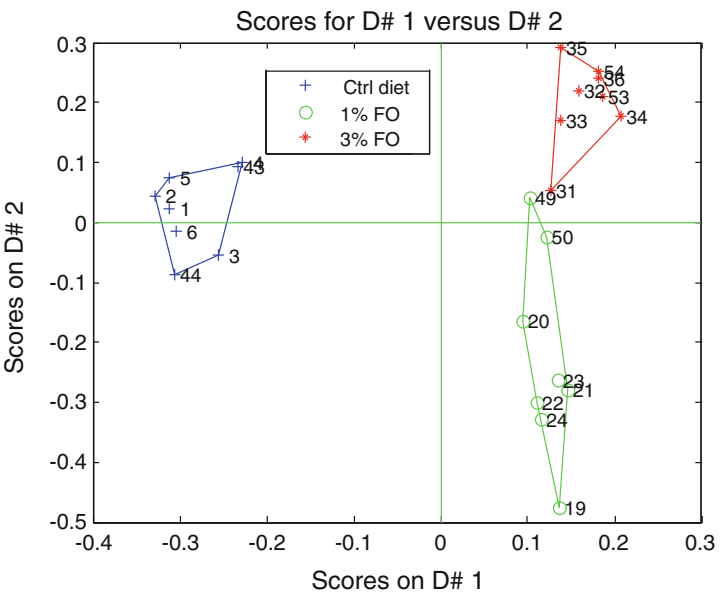

LPS

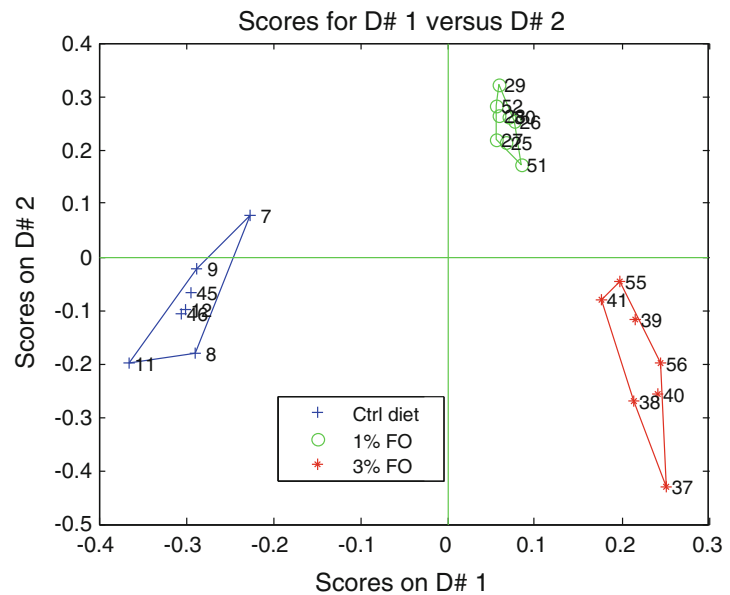

Fig. 3 PCDA analysis, split for saline and LPS treated mice. A separation of diet groups is observed in both saline and LPS treated mice, with a more prominent separation in the LPS treated mice

\section{Discussion}

Our results support the general idea that increasing dietary n-3 fatty intake results in increased levels of n-3 derivedendocannabinoids/NAEs and oxylipins. However, to the best of our knowledge, our study is the first one describing effects of dietary FO on the balance between the "endocannabinoid" and oxylipin pathways in such detail, in different compartments simultaneously, and in relation with inflammation. In addition, our study illustrates the risk of obtained potentially premature conclusions when only a few mediators are analyzed in a limited number of matrices. Several studies, focusing on for example AEA (anandamide) and 2-AG only, have concluded that dietary FO leads to an overall down regulation of the endocannabinoid system (Banni et al. 2011; Batetta et al. 2009). However, as we show other ( $\mathrm{n}-3$ derived-) endocannabinoids might be affected in an opposite direction following FO intake, and our data shows that the sum of all NAE levels in liver, ileum and plasma are actually quite stable with the different diets (data not shown). Although there are still several questions regarding their biological role, there are reports showing that $\mathrm{n}-3$ derived ethanolamides have affinity for CB1 and CB2 receptors (Brown et al. 2010; Plastina et al. 2009b), and have anti-inflammatory properties (Balvers et al. 2010; Meijerink et al. 2011).

LPS was found to produce a general increase of in vivo endocannabinoid/NAE and oxylipin levels, although there were some exceptions (see below). Multivariate data analysis showed that the diet effect was also present during inflammatory conditions. Without LPS, the effect of a FO diet was mainly explained by a reduction of mediators other than those derived from n-3 fatty acids, and to a lesser degree by increased levels of n-3 derived metabolites. However, after LPS, the balance was shifted in favor of an increase of n-3 derived mediators while lower associations were found with reductions of non n-3 derived metabolites.

The relation between dietary fatty acid intake and the presence of endocannabinoids/NAEs and oxylipins in plasma and tissues has been established before (Banni and Di Marzo 2010; Hansen and Artmann 2008), but not under conditions of inflammation. Previous work with rats demonstrated that patterns of organ levels of NAEs follow the relative abundance of fatty acids in the diet (Artmann et al. 2008). Other work, investigating the effect of DHA on murine levels of endocannabinoids/NAEs in brain and plasma, showed strongest changes in plasma (Wood et al. 2010). Interestingly, plasma AEA levels were not significantly affected by DHA alone, whereas other NAEs were decreased by DHA. Other work, supplementing krill oil or menhaden oil to human subjects also did not show an effect on plasma AEA levels (Banni et al. 2011). Our work shows that 6 weeks of a FO diet is capable of reducing plasma AEA and 2-AG levels. This discrepancy might originate from differences in n-3 fatty acids sources, daily dose, or length of the period in which the n-3 fatty acids were supplemented.

Many studies analyze plasma levels of endocannabinoids/NAEs or oxylipins. The present work shows that plasma levels do not always reflect effects in liver, ileum or adipose tissue. For example, plasma 2-AG levels decreased after LPS, but were increased in adipose tissue, and similar divergences were also observed for PEA, SEA, several HETEs, and $\mathrm{TBXB}_{2}$. The origin and significance of these findings are not known yet, but this could be related to synthesis, release, uptake or breakdown which might be differentially regulated by LPS or other factors across 
Table 6 Top lists for saline and LPS treated mice. Lists were generated from PCDA analysis, showing different patterns for saline and LPS treated mice

\begin{tabular}{|c|c|c|c|c|c|}
\hline & Saline & D-score & & LPS & D-score \\
\hline & P_AEA & $-4,6879$ & & L_2-AG & $-4,3994$ \\
\hline & L_2-AG & $-4,5742$ & & P_AEA & $-4,2737$ \\
\hline & P_DGLEA & $-4,5412$ & 1 & F_EPA & 4,2374 \\
\hline & F_AEA & $-4,4914$ & 2 & F_12-HEPE & 4,1634 \\
\hline & P_ARA & $-4,4486$ & 3 & P_EPA & 4,1441 \\
\hline & P_11,12-DiHETrE & $-4,4257$ & & P_2-AG & $-4,1053$ \\
\hline \multirow[t]{7}{*}{1} & F_DHEA & 4,3978 & & P_AA & $-4,0854$ \\
\hline & P_14,15-DiHETrE & $-4,3961$ & 4 & I_PGE 3 & 4,0450 \\
\hline & L_ARA & $-4,3915$ & 5 & $\mathbf{F}_{-} \mathbf{T B X B}_{3}$ & 4,0374 \\
\hline & $\mathrm{L}_{-} 13$,14-dihydro-15-keto-PGF $2 \mathrm{a}$ & $-4,3025$ & 6 & $\mathbf{F}_{-} \mathbf{P G E}_{3}$ & 3,9827 \\
\hline & L_12-HETE & $-4,2590$ & & P_DGLEA & $-3,9498$ \\
\hline & F_8,9-DiHETrE & $-4,2553$ & & L_14,15-DiHETrE & $-3,8977$ \\
\hline & L_15-HETE & $-4,2343$ & 7 & F_DHEA & 3,8946 \\
\hline \multirow[t]{2}{*}{2} & L_5-HEPE & 4,2162 & 8 & I_EPA & 3,8541 \\
\hline & L_11-HETE & $-4,1548$ & 9 & L_EPEA & 3,7505 \\
\hline 3 & L_EPA & 4,1323 & & L_11,12-DiHETrE & $-3,7410$ \\
\hline \multirow[t]{18}{*}{4} & P_EPA & 4,1269 & 10 & L_DHEA & 3,7222 \\
\hline & F_DGLEA & $-4,1166$ & & L_ARA & $-3,6999$ \\
\hline & P_8,9-DiHETrE & $-4,0892$ & 11 & L_EPA & 3,6953 \\
\hline & I_13,14-dihydro-15-keto-PGE 2 & $-4,0783$ & 12 & I_DHA & 3,6912 \\
\hline & P_OEA & $-4,0592$ & 13 & I_12-HEPE & 3,6874 \\
\hline & F_11,12 EET & $-4,0186$ & & L_8,9-DiHETrE & $-3,6672$ \\
\hline & F_OEA & $-4,0148$ & 14 & F_EPEA & 3,6327 \\
\hline & L_8,9-DiHETrE & $-4,0079$ & & $\mathrm{~L}_{-} 13,14$-dihydro-15-keto-PGF ${ }_{2 \mathrm{a}}$ & $-3,6261$ \\
\hline & I_2-AG & $-3,9897$ & & I_2-AG & $-3,6231$ \\
\hline & F_9,10-DiHOME & $-3,9147$ & 15 & P_DHA & 3,5903 \\
\hline & P_9,10-DiHOME & $-3,8645$ & & F_AEA & $-3,5678$ \\
\hline & L_LTB4 & 3,8175 & & $\mathrm{~L}_{-} \mathrm{PGD}_{2}$ & $-3,5455$ \\
\hline & F_11,12-DiHETrE & $-3,7600$ & 16 & $\mathbf{F}_{-} \mathbf{P G D}_{3}$ & 3,5197 \\
\hline & F_14,15-DiHETrE & $-3,7376$ & 17 & F_19,20-DiHoPE & 3,5168 \\
\hline & L_5,6 EET & $-3,7094$ & & L_AEA & $-3,5158$ \\
\hline & I_13,14-dihydro-15-keto-PGF $2 \mathrm{a}$ & $-3,7008$ & 18 & I_19,20-DiHoPE & 3,4924 \\
\hline & P_12,13-DiHOME & $-3,6962$ & & L_14,15 EET & $-3,4871$ \\
\hline & F_12,13-DiHOME & $-3,6718$ & 19 & I_EPEA & 3,4515 \\
\hline \multirow[t]{3}{*}{5} & P_DHEA & 3,6677 & 20 & I_5-HEPE & 3,4391 \\
\hline & P_UK4 & $-3,6605$ & & I_AEA & $-3,4310$ \\
\hline & L_14,15 EET & $-3,6511$ & & F_SEA & 3,4187 \\
\hline 6 & F_EPA & 3,6069 & & L_20-HETE & $-3,4104$ \\
\hline \multirow[t]{3}{*}{7} & I_19,20-DiHoPE & $\mathbf{3 , 5 9 3 8}$ & & I_13,14-dihydro-15-keto-PGE 2 & $-3,3956$ \\
\hline & F_5,6-DiHETrE & $-3,5357$ & 21 & P_5-HEPE & 3,3787 \\
\hline & P_2-AG & $-3,5155$ & 22 & L_5-HEPE & 3,3617 \\
\hline \multirow[t]{2}{*}{8} & I_12-HEPE & 3,4899 & & $\mathrm{~L}_{-} \mathrm{TBXB}_{2}$ & $-3,3200$ \\
\hline & L_11,12 EET & $-3,4781$ & & L_12-HHTrE & $-3,3155$ \\
\hline 9 & F_EPEA & 3,4723 & & P_5,6-DiHETrE & $-3,3080$ \\
\hline \multirow[t]{4}{*}{10} & L_19,20-DiHoPE & 3,4679 & 23 & F_5-HEPE & 3,3048 \\
\hline & L_12-HHTrE & $-3,4525$ & 24 & P_DHEA & 3,2978 \\
\hline & P_UK2 & $-3,4144$ & & P_11,12-DiHETrE & $-3,2966$ \\
\hline & $\mathrm{L}_{-} \mathrm{PGE}_{2}$ & $-3,4143$ & 25 & F_17 keto- 4(z), 7(z), 10(z), $13(\mathrm{z}), 15(\mathrm{E}), 19(\mathrm{z})$-DHA & 3,2931 \\
\hline
\end{tabular}


Table 6 continued

\begin{tabular}{llllr}
\hline & Saline & D-score & LPS & D-score \\
\hline 11 & I_EPA & $\mathbf{3 , 3 7 5 8}$ & L_11-HETE & $-3,2792$ \\
12 & P_5-HEPE & $\mathbf{3 , 3 5 8 1}$ & P_15-HETE & $-3,2618$ \\
\hline
\end{tabular}

The D-scores represent their weight, expressed as the numerical output value as obtained from the PCDA model; the further away from zero, the better this variable accounts for group separation. Negative scores indicate that the compound is decreased in the fish oil groups; positive scores mean that it is increased by fish oil. Decrease of other than n-3 derived compounds ranks relatively high in the saline diet effect, whereas an increase in $\mathrm{n}-3$ derived compounds (printed in bold) ranks high for the diet effect in the LPS treated mice

$P$ plasma, $L$ liver, $I$ ileum, $F$ adipose tissue

different organs. Nevertheless, based on our results, extrapolating effects found in plasma to effects on peripheral tissues is not always appropriate. It should be noted that the recovery of endogenous metabolites from tissues might not be complete, potentially underestimating actual effects of the diet and inflammation in the tissues.

The LPS treated mice had a lower food intake combined with a small loss of body weight (data not shown), whereas the saline treated animals displayed normal food consumption and stable body weight. Previous work showed that levels of endocannabinoids and related NAEs depend on fasting status (Hansen and Diep 2009; Joosten et al. 2010; Li et al. 2011); their tissue levels being high during fasting, followed by a rapid postprandial decrease. Possibly, the effect of LPS on endocannabinoid levels might in part be mediated through such a 'fasting' effect. In addition, inflammation reduces FAAH expression, and inhibition of FAAH or monoacyl glycerol lipase (MGL) has been shown to reduce disease symptoms in several models of inflammation (Alhouayek et al. 2011; Maccarrone et al. 2001; Naidu et al. 2010). Similarly, studies using CB2 knock-out models under induced inflammatory conditions showed that increased levels of NAEs likely contribute to suppress inflammation (Bátkai et al. 2007). Together, this suggests that increased levels of endocannabinoids/NAEs are part of a normal response protecting against inflammatory stress. Previous work identified DHEA and EPEA as having anti-inflammatory properties in macrophages and adipocytes (Balvers et al. 2010; Meijerink et al. 2011), and these compounds could be another link between FO and its anti-inflammatory effects as n-3 derived NAEs were more effective than AEA in suppressing nitric oxide release from macrophages (Meijerink et al. 2011).

The FO diets also influenced levels of oxylipins, including metabolites from the COX, CYP450, and 5-LOX, 12-LOX and 15-LOX pathways (Fig. 1), and these effects were in general also seen during inflammatory conditions. Another strength of the present study is that we analyzed both $n-6$ and $n-3$ related oxylipins simultaneously in different compartments. In general, levels of n-3 fatty acid derived oxylipins (e.g. $\mathrm{PGD}_{3}, \mathrm{PGE}_{3}$, 5-HEPE, 12-HEPE and $\mathrm{TBXB}_{3}$ ) were increased with $\mathrm{FO}$ at the expense of oxylipins derived from other fatty acids (e.g. $\mathrm{PGD}_{2}, \mathrm{PGE}_{2}, \mathrm{PGF}_{2 \alpha}, \mathrm{TBXB}_{2}$ and members of the EET and HETE subclasses). A functional role in inflammation has been described for several of these compounds, and it is likely that the changes in profiles which are found in this study (and before) are causally related to the anti-inflammatory effects which are associated with n-3 fatty acid intake. For example, $\mathrm{PGE}_{3}$ is less potent than $\mathrm{PGE}_{2}$ in inducing COX-2 expression and IL-6 release (Bagga et al. 2003). A similar principle applies to the thromboxanes (Fischer and Weber 1983; von Schacky et al. 1985) and for 5-HETE/5-HEPE (Heidel et al. 1989), which were also altered by the $\mathrm{FO}$ diets.

Interestingly, the FO diets increased liver $\mathrm{LTB}_{4}$ levels, whereas ileum $\mathrm{LTB}_{4}$ levels were decreased. $\mathrm{LTB}_{4}$ has multiple pro-inflammatory functions in the immune system (Calder 2003), but the different effect of FO on organ levels of $\mathrm{LTB}_{4}$ is not understood. Lipoxin $\mathrm{A}_{4}$, a compound with anti-inflammatory properties (Schwab and Serhan 2006), was increased by the $3 \%$ FO diet. This indicates that at least for this compound, which is synthesized from ARA, its levels are not directly related to dietary supply of precursors, but that other presently unknown factors are involved.

Levels of several EETs were reduced by the FO diets, especially in the liver. EETs play regulatory roles in heart and vascular physiology with effects on blood pressure regulation, but also have anti-inflammatory effects (Spector 2009). It thus seems that EETs do not play a role in the anti-inflammatory properties of n-3 fatty acids, but it should be noted that $n-3$ fatty acid derived EET analogues are reported to be endogenously present and have potent analgesic properties (Morisseau et al. 2010), but these specific EETs were not quantified in the current study. Another line of evidence suggests that EETs very specifically alter the release of either insulin or glucagon (Falck et al. 1983; Sacerdoti et al. 2003), pointing to a potential link between n-3 fatty acids and glucose metabolism. EETs might therefore also be part in mediating effects of dietary 
fatty acids on metabolism, but this relation has not been given much attention yet.

In the present study we did not detect resolvins in any of the samples. It might be that these compounds are not formed in quantities high enough to be detected with our method during the first $24 \mathrm{~h}$ after the initiation of the inflammatory response, or the detection limit of the analytical method was not sufficient to detect these compounds. The single timepoint approach in the present study is a limitation of the work, and investigating a broader time range, e.g. studying multiple time points beyond $24 \mathrm{~h}$ after the initiation of inflammation, might reveal temporal changes in lipid mediators including resolvins.

The presence of 17-HDoHE (also known as 17-HDHA), a marker for resolvin synthesis (Poulsen et al. 2008) with anti-inflammatory properties (González-Périz et al. 2006), was increased by the FO diets. The FO diets as well as LPS increased levels of 10,17-DiHDoHE, (also known as protectin DX) which was previously shown to reduce inflammation and accelerate its resolution (Serhan et al. 2006). Altogether, the FO diets altered all branches in the oxylipin metabolome in a way that is largely associated with suppression of inflammation.

A major finding of this work is that the effects of FO were also persistent under inflammatory conditions. Multivariate data analysis revealed that both endocannabinoids and oxylipins are responsible for separation between diet groups. Under non-inflammatory conditions, the diet groups could be primarily separated based on the reduction of other than n-3 derived endocannabinoids and oxylipins. In contrast, with LPS treatment, the diet groups were primarily separated by increases in levels of $n-3$ fatty acid derived endocannabinoids and oxylipins. The combined approach of comparing normal versus inflammatory conditions was thus useful in demonstrating that effects of diet on oxylipins and endocannabinoids are depending on inflammatory status.

Recent evidence suggested that relatively high intakes of FO impairs the host's resistance to microbial infection (Bonilla et al. 2010; Irons et al. 2003; Snel et al. 2010). In our study, the mice that had received $3 \%$ FO showed relatively more severe signs of shock after LPS, and one mouse from the $3 \%$ FO + LPS group died shortly before the end of the experiment. This would be in line with the notion that high FO intake might impair the host's resistance to inflammatory stress, or to suppress the capability to overcome the inflammatory stimulus. We observed that plasma $\mathrm{TBXB}_{2}$ levels, a compound related to $\mathrm{TBXA}_{2}$ which is involved in vasoconstriction (Sellers and Stallone 2008), was decreased in the $3 \%$ FO group compared to the $1 \%$ FO group, but also by LPS. The combination $3 \%$ FO and LPS treatment might have caused a decrease in $\mathrm{TBXA}_{2}$ levels below its physiological range, potentially increasing the risk of inducing excessive vasodilatation and shock. Alternatively, pre-treatment of rats with a CB1 blocker was effective in reducing hypotension after LPS administration (Varga et al. 1998), suggesting that increases in endocannabinoids after LPS might also contribute to the shock observed for the $3 \%$ FO + LPS group. Future work should point out which (combination of) metabolites account for the impaired resistance in the $3 \%$ FO + LPS group. Furthermore, future work should clarify which intake levels of n-3 fatty acids are beneficial to reduce symptoms of inflammatory diseases and where the inhibition of inflammation starts to interfere with an efficient response to an inflammatory stimulus.

In conclusion, dietary FO caused marked changes in the $n-3$ to $n-6$ balance of the endocannabinoid and oxylipin metabolomes, with specific effects depending on inflammatory status. The effects on metabolites are in line with the anti-inflammatory effects associated with $n-3$ fatty acid intake.

Acknowledgments The authors acknowledge M. Poland, A. Kreikamp and staff at the animal facility of Wageningen University for technical assistance, and staff and management of TNO Triskelion Ltd. (Zeist, The Netherlands) for facilitating the LC-MS analyses. This work was funded by a research grant from TNO (Balance/VP9).

Open Access This article is distributed under the terms of the Creative Commons Attribution License which permits any use, distribution, and reproduction in any medium, provided the original author(s) and the source are credited.

\section{References}

Alhouayek, M., Lambert, D. M., Delzenne, N. M., Cani, P. D., \& Muccioli, G. G. (2011). Increasing endogenous 2-arachidonoylglycerol levels counteracts colitis and related systemic inflammation. FASEB Journal, 25(1), 2711-2721.

Artmann, A., Petersen, G., Hellgren, L. I., Boberg, J., Skonberg, C., Nellemann, C., et al. (2008). Influence of dietary fatty acids on endocannabinoid and $\mathrm{N}$-acylethanolamine levels in rat brain, liver and small intestine. Biochimica et Biophysica Acta (BBA): Molecular and Cell Biology of Lipids, 1781(4), 200-212.

Bagga, D., Wang, L., Farias-Eisner, R., Glaspy, J. A., \& Reddy, S. T. (2003). Differential effects of prostaglandin derived from w-6 and $w-3$ polyunsaturated fatty acids on COX-2 expression and IL-6 secretion. Proceedings of the National Academy of Sciences, 100(4), 1751-1756.

Balvers, M. G. J., Verhoeckx, K. C. M., Plastina, P., Wortelboer, H. M., Meijerink, J., \& Witkamp, R. F. (2010). Docosahexaenoic acid and eicosapentaenoic acid are converted by 3T3-L1 adipocytes to $\mathrm{N}$-acyl ethanolamines with anti-inflammatory properties. Biochimica et Biophysica Acta (BBA): Molecular and Cell Biology of Lipids, 1801(10), 1107-1114.

Balvers, M. G. J., Verhoeckx, K. C. M., \& Witkamp, R. F. (2009). Development and validation of a quantitative method for the determination of 12 endocannabinoids and related compounds in human plasma using liquid chromatography-tandem mass 
spectrometry. Journal of Chromatography B, 877(14-15), $1583-1590$.

Banni, S., Carta, G., Murru, E., Cordeddu, L., Giordano, E., Sirigu, A., et al. (2011). Krill oil significantly decreases 2-arachidonoylglycerol plasma levels in obese subjects. Nutrition and Metabolism, 8(1), 7

Banni, S., \& Di Marzo, V. (2010). Effect of dietary fat on endocannabinoids and related mediators: Consequences on energy homeostasis, inflammation and mood. Molecular Nutrition and Food Research, 54(1), 82-92.

Batetta, B., Griinari, M., Carta, G., Murru, E., Ligresti, A., Cordeddu, L., et al. (2009). Endocannabinoids may mediate the ability of $(n-3)$ fatty acids to reduce ectopic fat and inflammatory mediators in obese zucker rats. Journal of Nutrition, 139(8), $1495-1501$.

Bátkai, S., Osei-Hyiaman, D., Pan, H., El-Assal, O., Rajesh, M., Mukhopadhyay, P., et al. (2007). Cannabinoid-2 receptor mediates protection against hepatic ischemia/reperfusion injury. FASEB Journal, 21(8), 1788-1800.

Benjamini, Y., \& Hochberg, Y. (1995). Controlling the false discovery rate: A practical and powerful approach to multiple testing. Journal of the Royal Statistical Society (Methodological), 57(1), 289-300.

Berger, A., Crozier, G., Bisogno, T., Cavaliere, P., Innis, S., \& Di Marzo, V. (2001). Anandamide and diet: Inclusion of dietary arachidonate and docosahexaenoate leads to increased brain levels of the corresponding $\mathrm{N}$-acylethanolamines in piglets. Proceedings of the National academy of Sciences of the United States of America, 98(11), 6402-6406.

Bisogno, T. (2008). Endogenous cannabinoids: Structure and metabolism. Journal of Neuroendocrinology, 20(Suppl. 1), 1-9.

Bonilla, D., Ly, L., Fan, Y.-Y., Chapkin, R., \& McMurray, D. (2010). Incorporation of a dietary omega 3 fatty acid impairs murine macrophage responses to Mycobacterium tuberculosis. PLoS One, 5(5), 5e10878.

Brown, I., Cascio, M. G., Wahle, K. W. J., Smoum, R., Mechoulam, R., Ross, R. A., et al. (2010). Cannabinoid receptor-dependent and -independent anti-proliferative effects of omega-3 ethanolamides in androgen receptor-positive and -negative prostate cancer cell lines. Carcinogenesis, 31(9), 1584-1591.

Calder, P. C. (2003). Long-chain n-3 fatty acids and inflammation: Potential application in surgical and trauma patients. Brazilian Journal of Medical and Biological Research, 36, 36433-36446.

Calder, P. C. (2006). n-3 Polyunsaturated fatty acids, inflammation, and inflammatory diseases. The American Journal of Clinical Nutrition, 83(6), S1505-1519S.

Calder, P. C. (2009a). Polyunsaturated fatty acids and inflammatory processes: New twists in an old tale. Biochimie, 91(6), 791-795.

Calder, P. C. (2009b). The relationship between the fatty acid composition of immune cells and their function. Prostaglandins Leukotrienes and Essential Fatty Acids, 79(3-5), 101-108.

Carpentier, Y. A., Portois, L., \& Malaisse, W. J. (2006). n-3 Fatty acids and the metabolic syndrome. American Journal of Clinical Nutrition, 83(6), S1499-S1504.

Cencioni, M. T., Chiurchiù, V., Catanzaro, G., Borsellino, G., Bernardi, G., Battistini, L., et al. (2010). Anandamide suppresses proliferation and cytokine release from primary human T-lymphocytes mainly via $\mathrm{CB}_{2}$ receptors. PLoS One, 5(1), e8688.

De Petrocellis, L., Melck, D., Bisogno, T., \& Di Marzo, V. (2000). Endocannabinoids and fatty acid amides in cancer, inflammation and related disorders. Chemistry and Physics of Lipids, 108(1-2), 191-209.

Di Marzo, V. (2008). The endocannabinoid system in obesity and type 2 diabetes. Diabetologia, 51(8), 1356-1367.

Falck, J. R., Manna, S., Moltz, J., Chacos, N., \& Capdevila, J. (1983). Epoxyeicosatrienoic acids stimulate glucagon and insulin release from isolated rat pancreatic islets. Biochemical and Biophysical Research Communications, 114(2), 743-749.

Fischer, S., \& Weber, P. C. (1983). Thromboxane A3 (TXA3) is formed in human platelets after dietary eicosapentaenoic acid (C20:5[omega]3). Biochemical and Biophysical Research Communications, 116(3), 1091-1099.

González-Périz, A., Planagumà, A., Gronert, K., Miquel, R., LópezParra, M., Titos, E., et al. (2006). Docosahexaenoic acid (DHA) blunts liver injury by conversion to protective lipid mediators: Protectin D1 and 17S-hydroxy-DHA. FASEB Journal, 20(14), 2537-2539.

Hansen, H. S., \& Artmann, A. (2008). Endocannabinoids and Nutrition. Journal of Neuroendocrinology, 20(1), 94-99.

Hansen, H. S., \& Diep, T. A. (2009). N-acylethanolamines, anandamide and food intake. Biochemical Pharmacology, 78(1), 553-560.

Heidel, J., Taylor, S., Laegreid, W., Silflow, R., Liggitt, H., \& Leid, R. (1989). In vivo chemotaxis of bovine neutrophils induced by 5-lipoxygenase metabolites of arachidonic and eicosapentaenoic acid. American Journal of Pathology, 134(3), 671-676.

Hoogerbrugge, R., Willig, S. J., \& Kistemaker, P. G. (1983). Discriminant analysis by double stage principal component analysis. Analytical Chemistry, 397, 551710-551712.

Irons, R., Anderson, M. J., Zhang, M., \& Fritsche, K. L. (2003). Dietary fish oil impairs primary host resistance against Listeria monocytogenes more than the immunological memory response. The Journal of Nutrition, 133(4), 1163-1169.

Joliffe, I. T. (1986). Principal Component Analysis. Springer Verlag, New York

Joosten, M., Balvers, M., Verhoeckx, K., Hendriks, H., \& Witkamp, R. (2010). Plasma anandamide and other N-acylethanolamines are correlated with their corresponding free fatty acid levels under both fasting and non-fasting conditions in women. Nutrition and Metabolism, 7(1), 49.

Li, C., Jones, P. M., \& Persaud, S. J. (2011). Role of the endocannabinoid system in food intake, energy homeostasis and regulation of the endocrine pancreas. Pharmacology and Therapeutics, 129(3), 307-320.

Maccarrone, M., De Petrocellis, L., Bari, M., Fezza, F., Salvati, S., Di Marzo, V., et al. (2001). Lipopolysaccharide downregulates fatty acid amide hydrolase expression and increases anandamide levels in human peripheral lymphocytes. Archives of Biochemistry and Biophysics, 393(2), 321-328.

Matias, I., Gonthier, M. P., Orlando, P., Martiadis, V., De Petrocellis, L., Cervino, C., et al. (2006). Regulation, function, and dysregulation of endocannabinoids in models of adipose and b-pancreatic cells and in obesity and hyperglycemia. Journal of Clinical Endocrinology and Metabolism, 91(8), 3171-3180.

Meijerink, J., Plastina, P., Vincken, J.-P., Poland, M., Attya, M., Balvers, M. G. et al. (2011). The ethanolamide metabolite of DHA, docosahexaenoylethanolamine, shows immunomodulating effects in mouse peritoneal and RAW264.7 macrophages: evidence for a new link between fish oil and inflammation. British Journal of Nutrition, 105(1), 1798-1807.

Morisseau, C., Inceoglu, B., Schmelzer, K., Tsai, H., Jinks, S., Hegedus, C., et al. (2010). Naturally occuring monoepoxides of eicosapentaenoic acid and docosahexaenoic acid are bioactive antihyperalgesic lipids. Journal of Lipid Research, 51(12), 3481-3490.

Naidu, P. S., Kinsey, S. G., Guo, T. L., Cravatt, B. F., \& Lichtman, A. H. (2010). Regulation of inflammatory pain by inhibition of fatty acid amide hydrolase. Journal of Pharmacology and Experimental Therapeutics, 334(1), 182-190.

Oh, D. Y., Talukdar, S., Bae, E. J., Imamura, T., Morinaga, H., Fan, W., et al. (2010). GPR120 is an omega-3 fatty acid receptor mediating potent anti-inflammatory and insulin-sensitizing effects. Cell, 142(5), 687-698. 
O’Sullivan, S. E. (2007). Cannabinoids go nuclear: Evidence for activation of peroxisome proliferator-activated receptors. British Journal of Pharmacology, 152(5), 576-582.

Plastina, P., Meijerink, J., Vincken, J.-P., Gruppen, H., Witkamp, R., \& Gabriele, B. (2009a). Selective synthesis of unsaturated $\mathrm{N}$-acylethanolamines by lipase-catalyzed $\mathrm{N}$-acylation of ethanolamine with unsaturated fatty acids. Letters in Organic Chemistry, 6(1), 444-447.

Plastina, P., Meijerink, J., Vincken, J.-P., Poland, M., \& Witkamp, R. F. (2009b). Inhibition of nitric oxide production in RAW264.7 macrophages by $\mathrm{N}$-acyl ethanolamides. Naunyn-Schmiedebergs, Archives of Pharmacology, 380(1), 268.

Poulsen, R. C., Gotlinger, K. H., Serhan, C. N., \& Kruger, M. C. (2008). Identification of inflammatory and proresolving lipid mediators in bone marrow and their lipidomic profiles with ovariectomy and omega-3 intake. American Journal of Hematology, 83(6), 437-445.

Re, G., Barbero, R., Miolo, A., \& Di Marzo, V. (2007). Palmitoylethanolamide, endocannabinoids and related cannabimimetic compounds in protection against tissue inflammation and pain: Potential use in companion animals. The Veterinary Journal, 173(1), 21-30.

Sacerdoti, D., Gatta, A., \& McGiff, J. C. (2003). Role of cytochrome $\mathrm{P} 450-$ dependent arachidonic acid metabolites in liver physiology and pathophysiology. Prostaglandins and Other Lipid Mediators, 72(1-2), 51-71.

Schmitz, G., \& Ecker, J. (2008). The opposing effects of n-3 and n-6 fatty acids. Progress in Lipid Research, 47(2), 147-155.

Schwab, J. M., \& Serhan, C. N. (2006). Lipoxins and new lipid mediators in the resolution of inflammation. Current Opinion in Pharmacology, 6(4), 414-420.

Sellers, M. M., \& Stallone, J. N. (2008). Sympathy for the devil: the role of thromboxane in the regulation of vascular tone and blood pressure. American Journal of Physiology: Heart and Circulatory Physiology, 294(5), H1978-H1986.
Serhan, C., Arita, M., Hong, S., \& Gotlinger, K. (2004). Resolvins, docosatrienes, and neuroprotectins, novel omega-3-derived mediators, and their endogenous aspirin-triggered epimers. Lipids, 39(11), 1125-1132.

Serhan, C. N., Gotlinger, K., Hong, S., Lu, Y., Siegelman, J., Baer, T., et al. (2006). Anti-inflammatory actions of neuroprotectin D1/ protectin D1 and its natural stereoisomers: Assignments of dihydroxy-containing docosatrienes. The Journal of Immunology, 176(3), 1848-1859.

Snel, J., Born, L., \& Van Der Meer, R. (2010). Dietary fish oil impairs induction of g-interferon and delayed-type hypersensitivity during a systemic Salmonella enteritidis infection in rats. APMIS, 118(8), 578-584.

Spector, A. A. (2009). Arachidonic acid cytochrome P450 epoxygenase pathway. Journal of Lipid Research, 50(Supplement), S52-S56.

Ueda, N., Tsuboi, K., \& Uyama, T. (2010). Enzymological studies on the biosynthesis of N-acylethanolamines. Biochimica et Biophysica Acta (BBA): Molecular and Cell Biology of Lipids, 1801(12), 1274-1285.

Varga, K., Wagner, J. A., Bridgen, D. T., \& Kunos, G. (1998). Platelet- and macrophage-derived endogenous cannabinoids are involved in endotoxin-induced hypotension. FASEB Journal, 12(11), 1035-1044.

von Schacky, C., Fischer, S., \& Weber, P. C. (1985). Long-term effects of dietary marine omega- 3 fatty acids upon plasma and cellular lipids, platelet function, and oxylipin formation in humans. The Journal of Clinical Investigation, 76(4), $1626-1631$.

Wood, J. T., Williams, J. S., Pandarinathan, L., Janero, D. R., LammiKeefe, C. J., \& Makriyannis, A. (2010). Dietary docosahexaenoic acid supplementation alters select physiological endocannabinoid-system metabolites in brain and plasma. Journal of Lipid Research, 51(6), 1416-1423. 